\author{
Military Technical College \\ Kobry El-Kobbah, \\ Cairo, Egypt
}

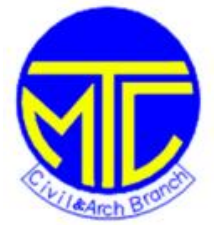

$9^{\text {th }}$ International Conference on Civil and Architecture Engineering

ICCAE-5-2012

\title{
Structural Analysis for Upgrading Metallic Rigidly Connected Floating Bridge Using 3D FEM
}

\author{
Y. A. Khalifa*, M. M. Abdelwahab*, and Adel Helmy Salem*
}

\begin{abstract}
Continuous floating bridges are the most usable type of floating bridges in military operations. It is called the assault launching bridges, their units (pontoons) are carried on vehicles and easily thrown in the water barrier and then self mechanically opened. The pontoons are rigidly connected by compression connections at upper side in addition to tension connections at lower side.

3D FEM for continuous floating bridge is done to analyze the stability of this type of bridges under traffic loading in addition to hydrostatic forces exerted by surrounding water media.

This paper presents the analysis of the old (existing) rigidly connected floating bridge under MLC 60 and MLC70, in order to find the points of weakness, and to understand the behavior of the bridge. Then, another analysis is done for the modified floating bridge under MLC 70. Comparison is done between old and modified bridges.
\end{abstract}

\section{KEYWORDS:}

Floating bridge; Pontoons; 3D FEM; Military Load Capacity 70ton (MLC70).

\section{INTRODUCTION}

Continuous floating bridges are the most usable type of floating bridges in military operations. It is called the assault launching bridges, their units (pontoons) are carried on vehicles and easily thrown in the water barrier and then self mechanically opened. The pontoons are rigidly connected by compression connections at upper side in addition to tension connections at lower side.

3D FEM for continuous floating bridge is done to analyze the behavior and stabili ty of this type of bridges under traffic loading in addition to hydrostatic forces exerted by surrounding water media. Lateral support for such floating bridges can be done either by using boats in opposite direction to the water follow or by using mooring cables. Boats are widely used for temporary military floating bridges for quick installation, Lateral forces and Stability aren't taken into consideration in the analysis of this paper. Military load capacity of 70 ton is taken as the ruling load of the following analysis.

*_Military Technical College, Cairo, Egypt, khalifa_yaser@yahoo.com. 


\section{PROBLEM STATEMENT}

The main objective of this paper is to analyze the old (existing) continuous bridge under MLC60 and MLC70, in order to find the points of weakness, and to understand the behavior of the bridge. Then, another analysis is done for the modified (upgraded) floating bridges under MLC 70. Comparison is done between old and modified bridges.

\section{MODEL DESCRIPTION}

Continuous pontoon bridge of length $114 \mathrm{~ms}$, width $8 \mathrm{~ms}$ and height $0.75 \mathrm{~m}$ was taken as our case. The bridge is composed of five ferries (bridge bays) rigidly connected together. Shell elements were used to model bridge bays and its internal construction. Solid elements were used to model the connectors between the bridge bays.

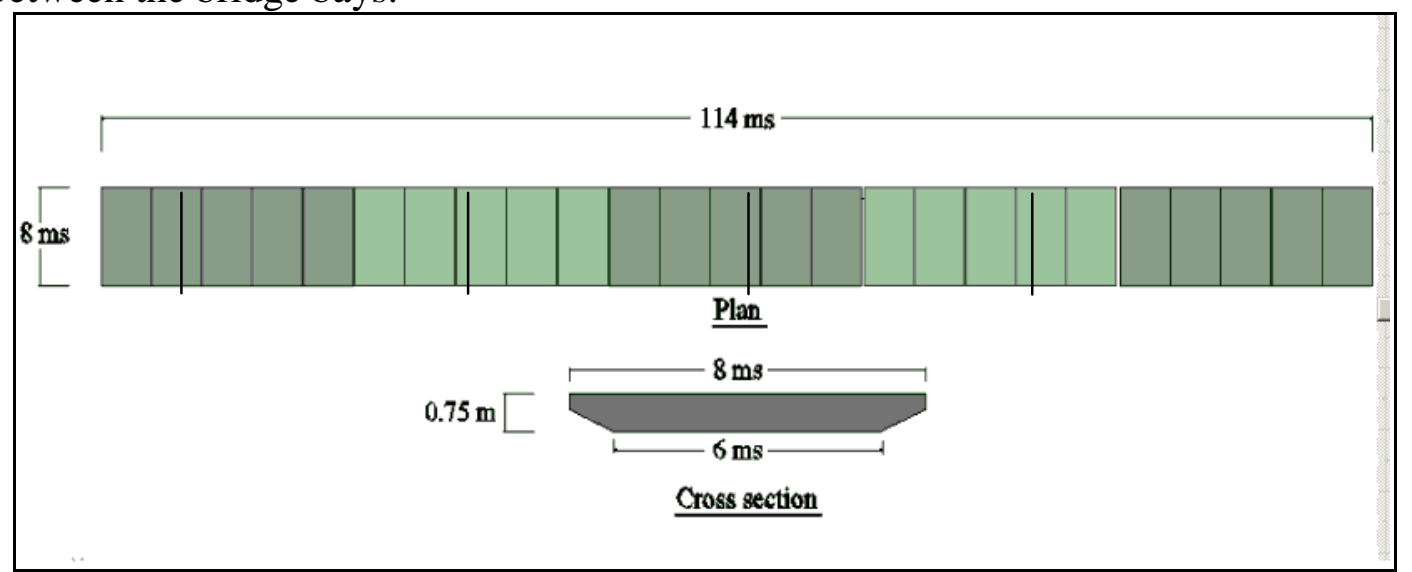

Figure (3.1) Continuous pontoon bridge model dimensions

The bridge is hinged supported at ends, which represent the effect of the shore pontoon on the bridge. Water bouncy forces are simulated as elastic supports acting on the contact surface of the bridge. Own weight of the bridge is taken into consideration.

\section{Single tank loading}

First, a single tank load is used as a traffic loading for the floating bridge. Two cases of single tank loading are considered to show the critical cases (at middle of the bridge and just after the connection of the middle bridge bay) as shown in figure (4.1) and (4.2). 


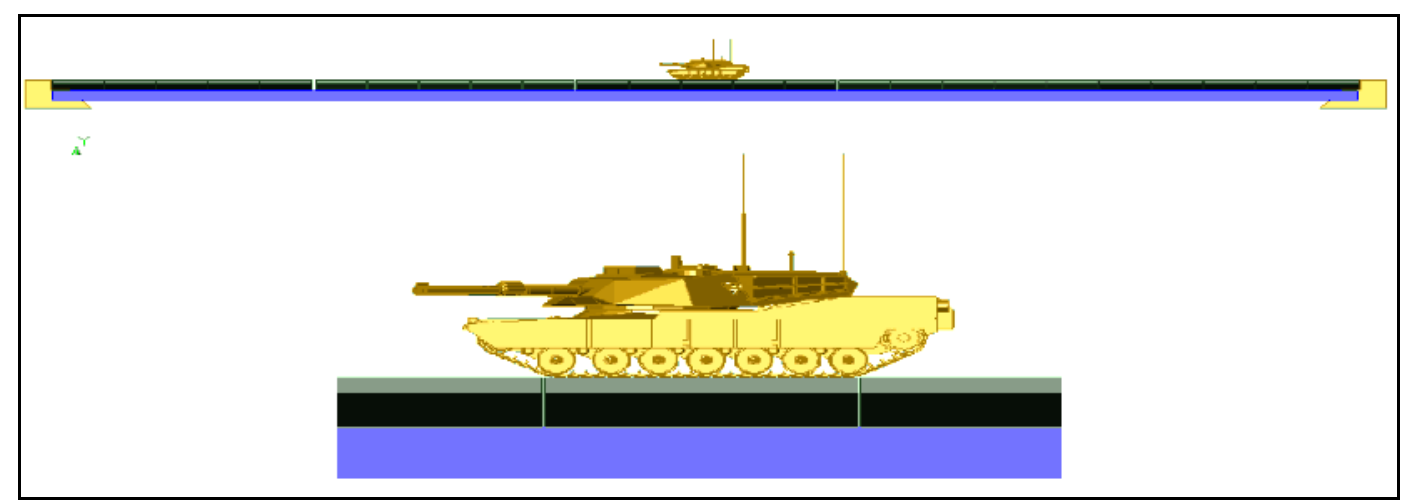

Figure (4.1) Load case-1 (concentric loading)

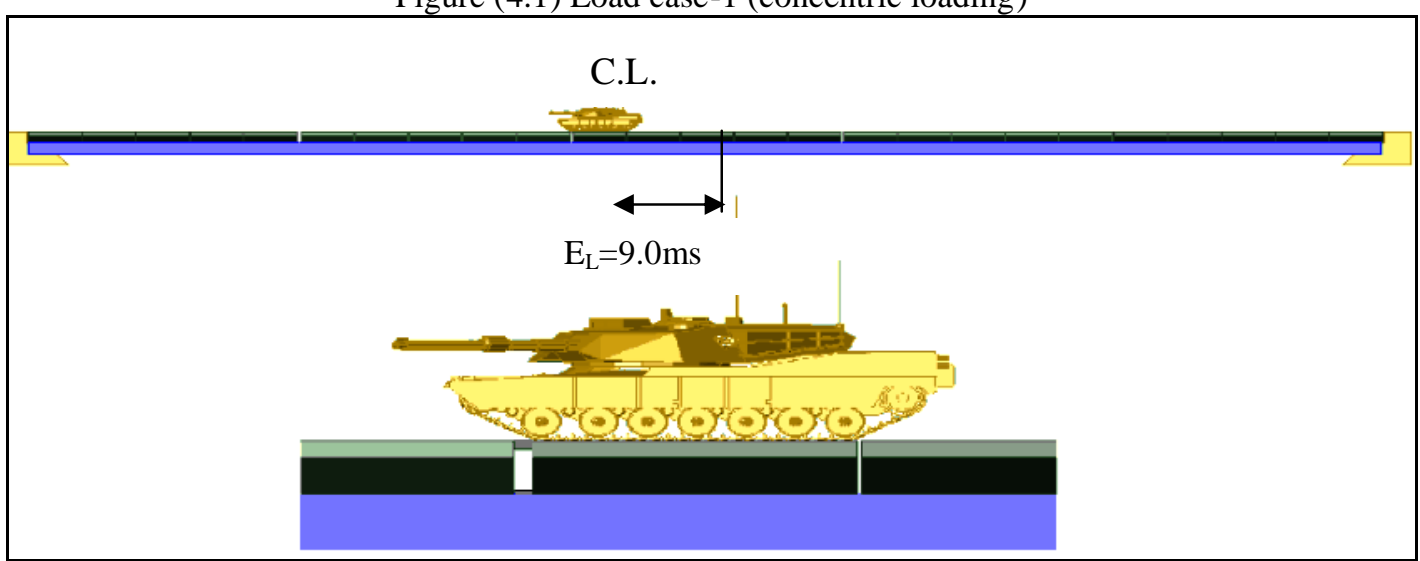

Figure (4.2) Load case-2 (longitudinal eccentricity $=9.0 \mathrm{~ms}$ )

\subsection{Single tank MLC60 loading}

The MLC60 load is used in order to analyze the existing bridge, under its design load and to show the behavior of the bridge. The draft values under such case shall be a reference for the bridge draft in the other cases of analysis.

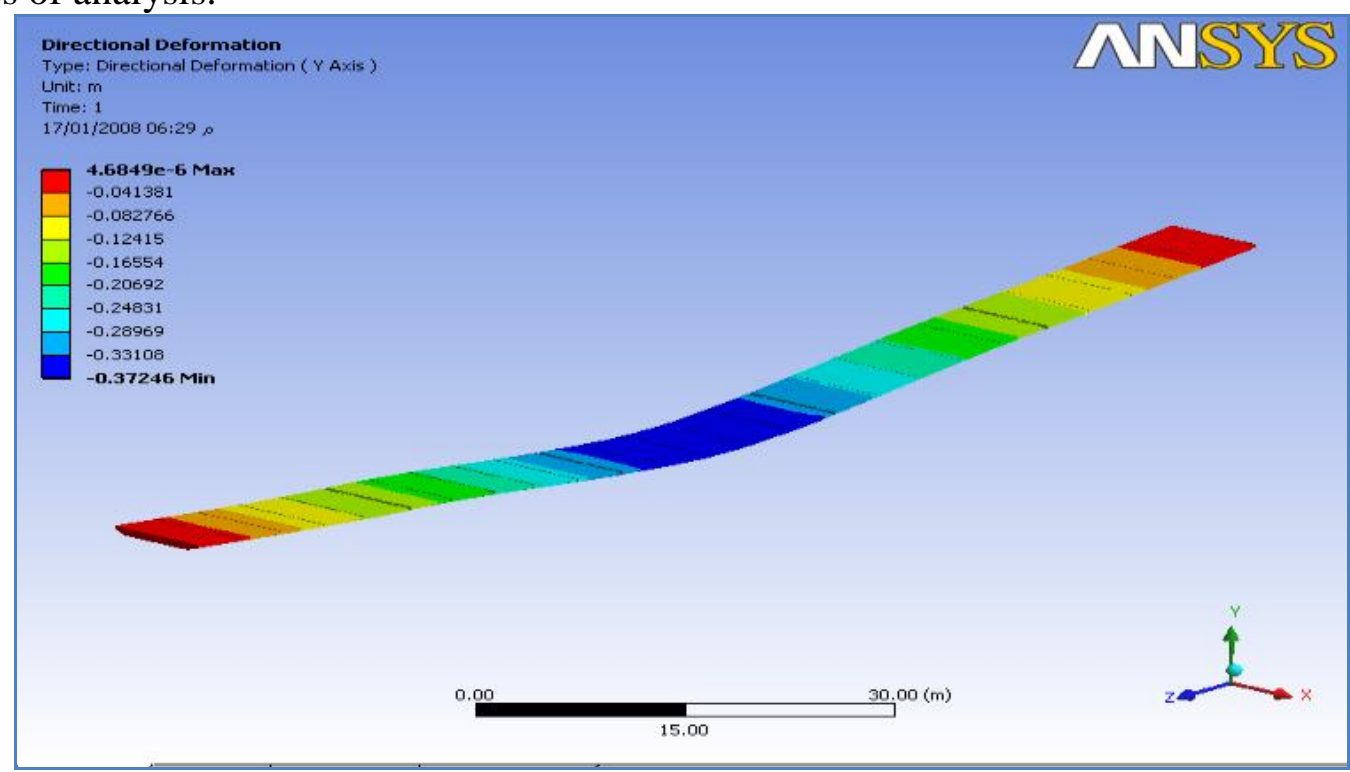

Figure (4.1.1) Draft of the continuous bridge under single MLC60 (concentric loading) 


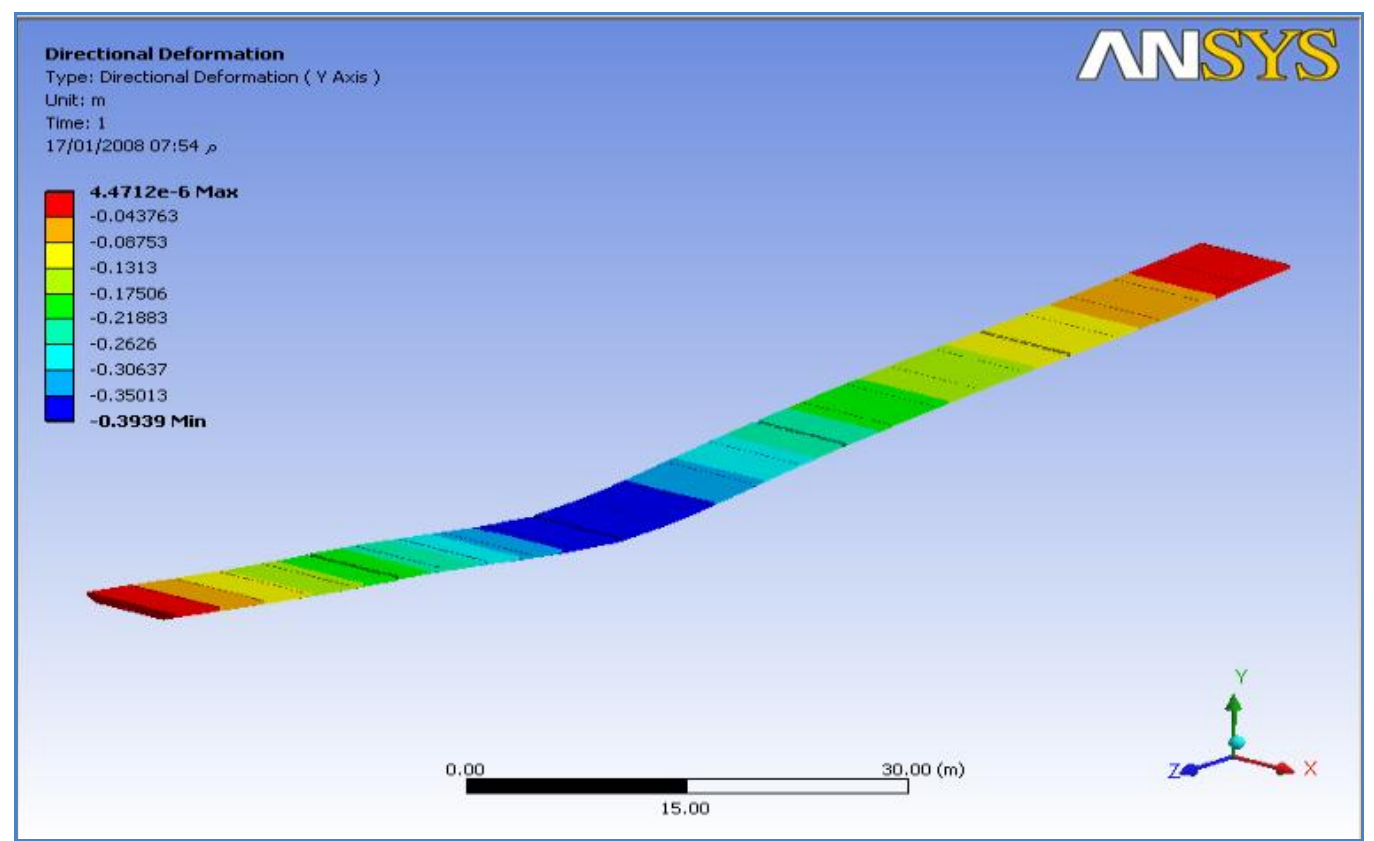

Figure (4.1.2) Draft of the continuous bridge under single MLC 60 (longitudinal eccentricity $=9.0 \mathrm{~ms}$ )

The analysis of the shown bridge under single load (MLC60) as shown in figures (4.1.1) and (4.1.2) shows that the maximum draft is found to be $37 \mathrm{cms}$ under the first loading case when the tank is on the middle of the bridge which represents $49.3 \%$ of the bridge height, while it is found to be $39.4 \mathrm{cms}$ under the second loading case which represents $52.5 \%$ of the bridge height. The reason of the low values of draft in case of bridge than that in case of the ferry is that the bridge acts as one unit floating on the surface of water and the reaction of the water affects all length of the bridge, while in case of ferry the length of action is much lesser.

\subsection{Single tank MLC70 loading}

The analysis of the old existing bridge under MLC 70 is done to study the differences in the output values of the analysis. Also, this analysis shall be used in the comparison between the old and modified bridges under MLC70. 


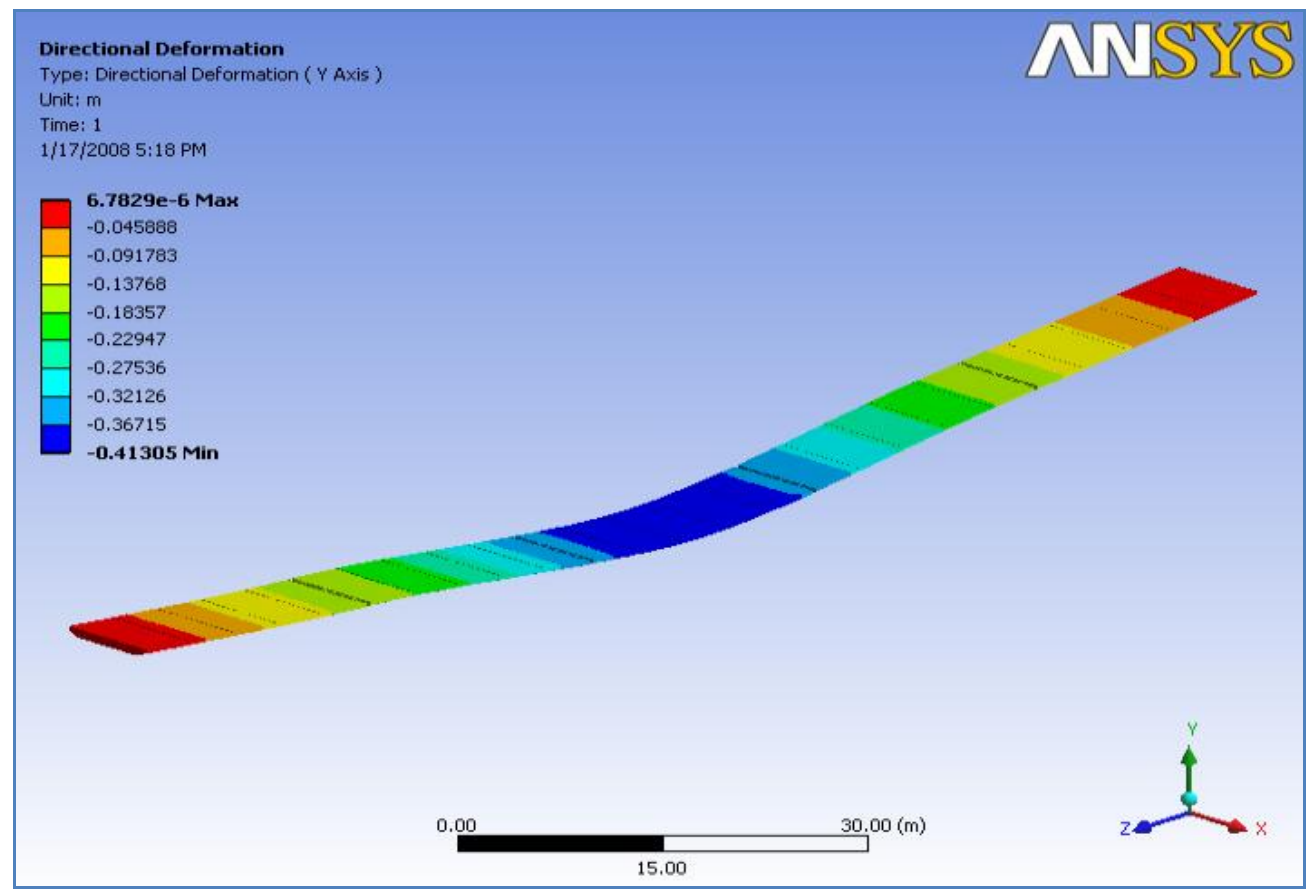

Figure (4.2.1) Draft of the continuous bridge under single MLC 70 (concentric loading)

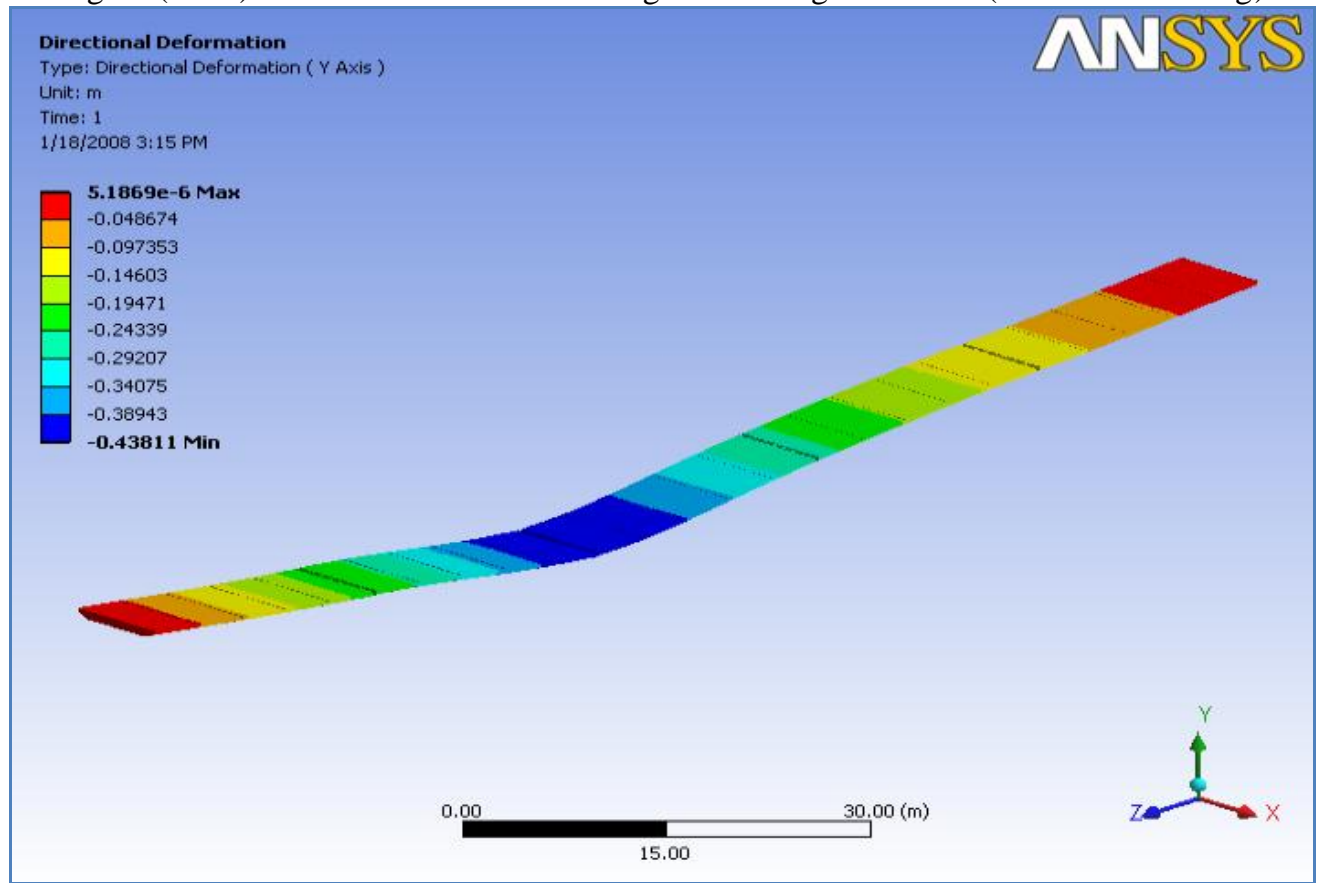

Figure (4.2.2) Draft of the continuous bridge under single MLC 70 (longitudinal eccentricity $=9.0 \mathrm{~ms}$ )

The 3D FEM of the old bridge under single load (MLC70) shows that the maximum draft is found to be $41.3 \mathrm{cms}$ under the first loading case when the tank is in the middle of the bridge and this value represents $55 \%$ of the bridge height and $12 \%$ increase than that under MLC 60, while it is found to be $43.8 \mathrm{cms}$ under the second loading case which represents $58.4 \%$ of the bridge height and $12 \%$ increase than that under MLC60. The draft diagrams are illustrated in figures (4.2.1) and (4.2.2).

\subsection{Single tank MLC70 loading on the modified bridge}


The modified bridge shown in figure (4.3.1) is analyzed under single MLC70 to show how much the modification affected the output values of the analysis.

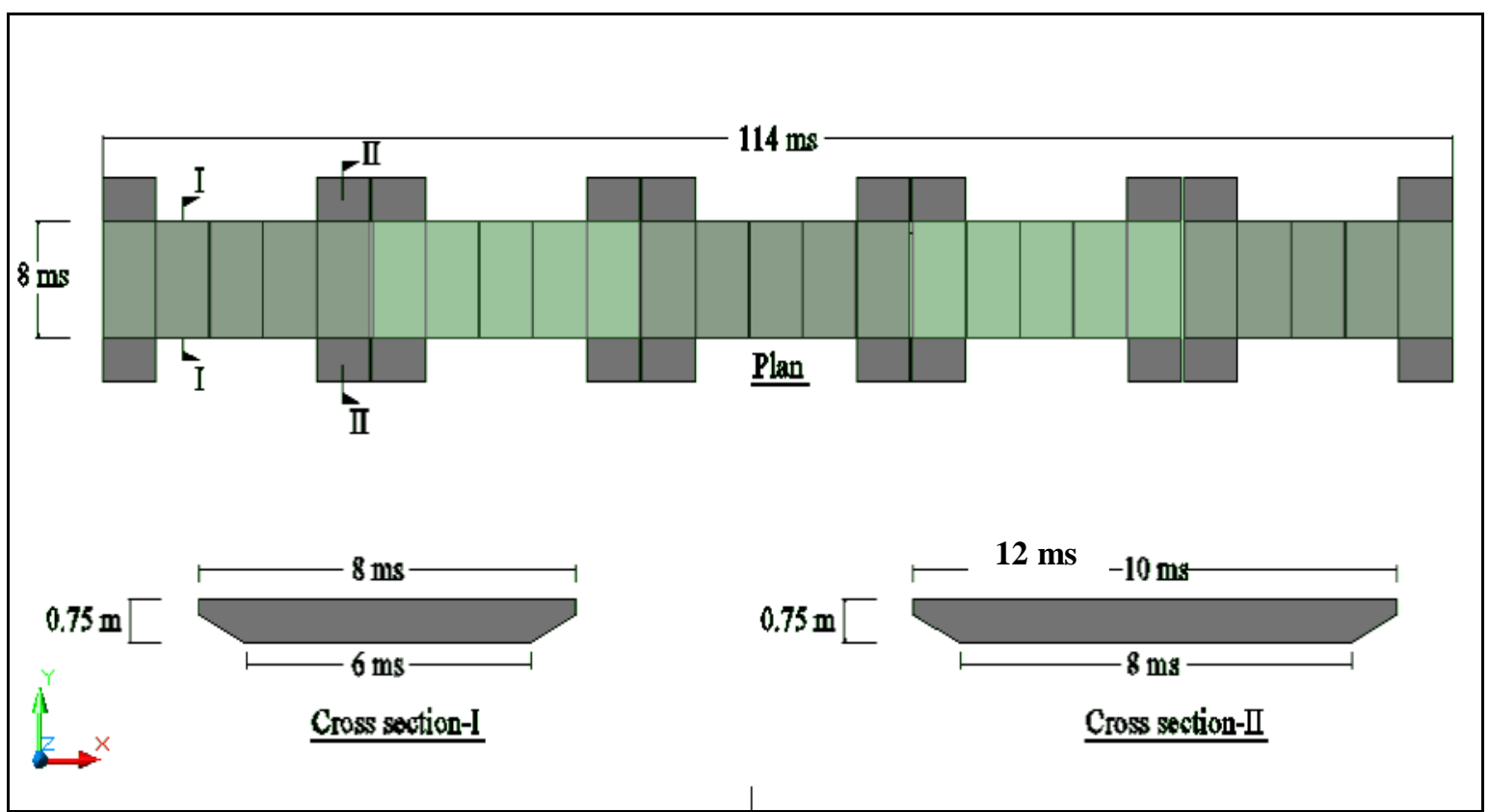

Figure (4.3.1) Continuous pontoon modified bridge model dimensions

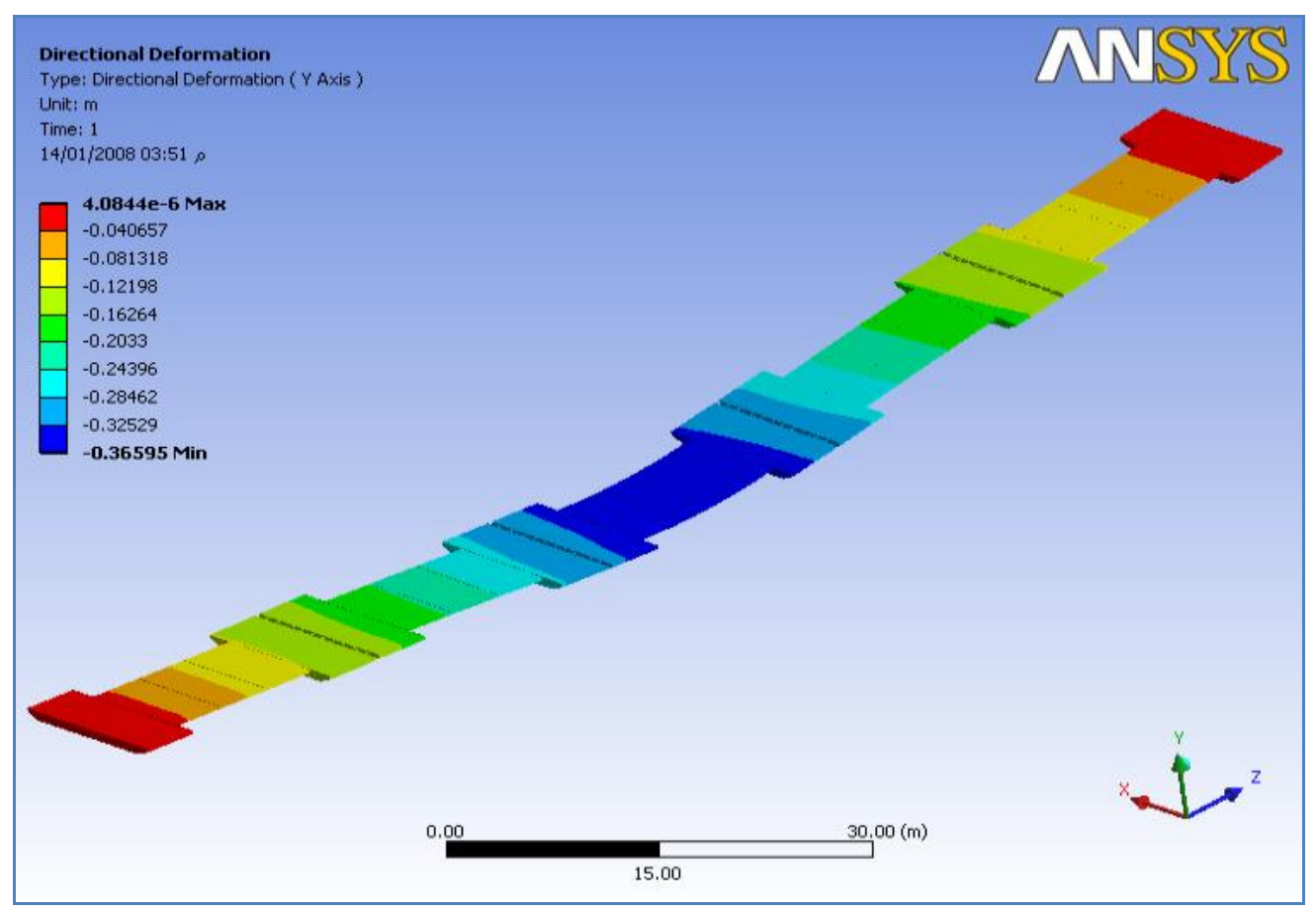

Figure (4.3.2) Draft of the continuous modified bridge under single MLC 70 (concentric loading) 


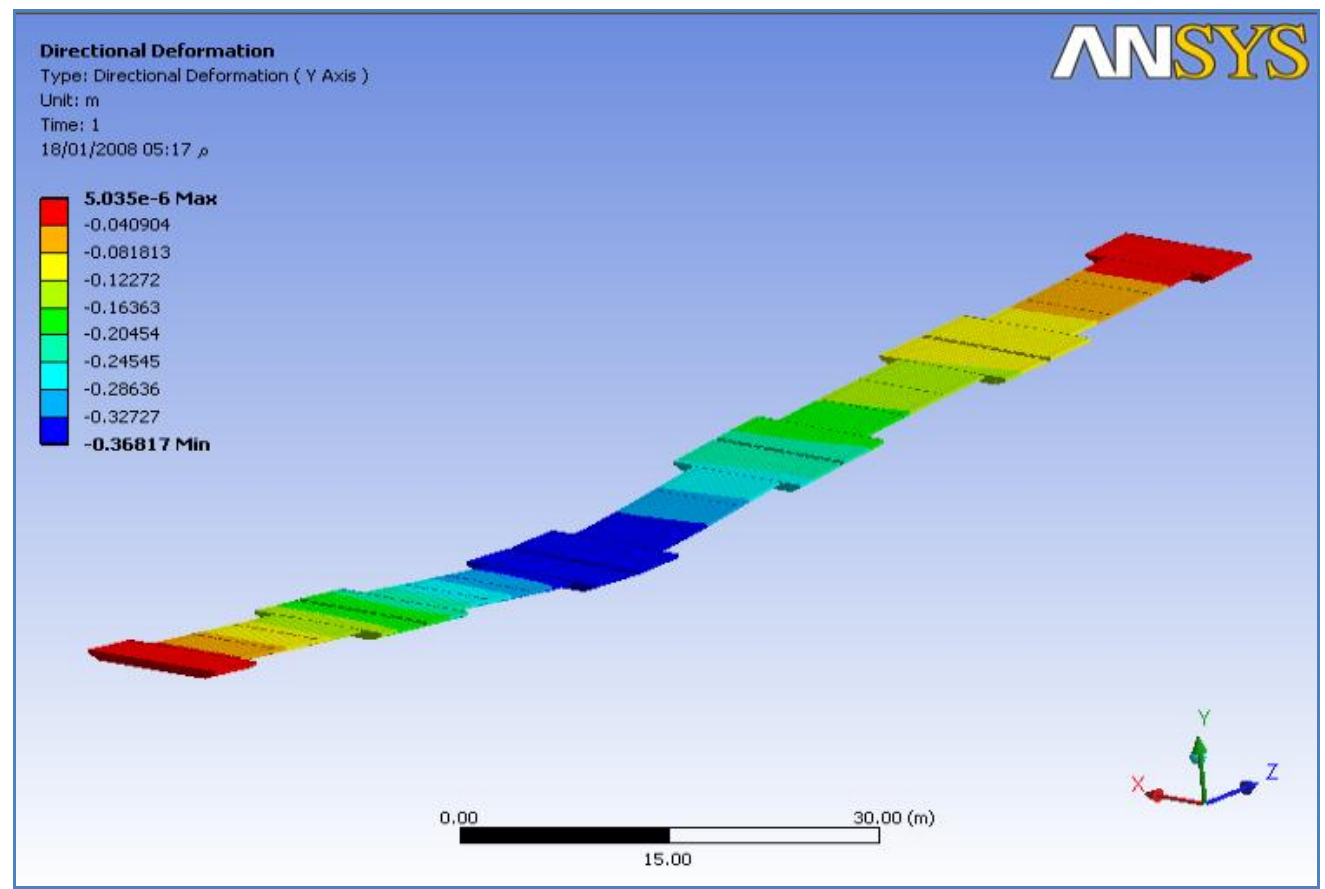

Figure (4.3.3) Draft of the continuous modified bridge under single MLC 70 (longitudinal eccentricity $=9.0 \mathrm{~ms}$ )

As shown in figures (4.3.2) and (4.3.3) the analysis of the modified continuo us bridge under single load (MLC70), the maximum draft was found to be $36.5 \mathrm{cms}$ under the first loading case when the tank was in the middle of the bridge and this value represents $48.7 \%$ of the bridge height, while it was found to be $36.8 \mathrm{cms}$ under the second loading case which represents $49 \%$ of the bridge height. The draftdistance curves for the three models studied i.e. old existing bridge under MLC60, old existing bridge under MLC70 and the modified bridge under MLC 70 are shown in figures (4.3.4) and (4.3.5). The modification reduced the draft/depth and decreased its values by $12 \%$ and $19 \%$ for first and second cases respectively as shown in figure (4.3.4).

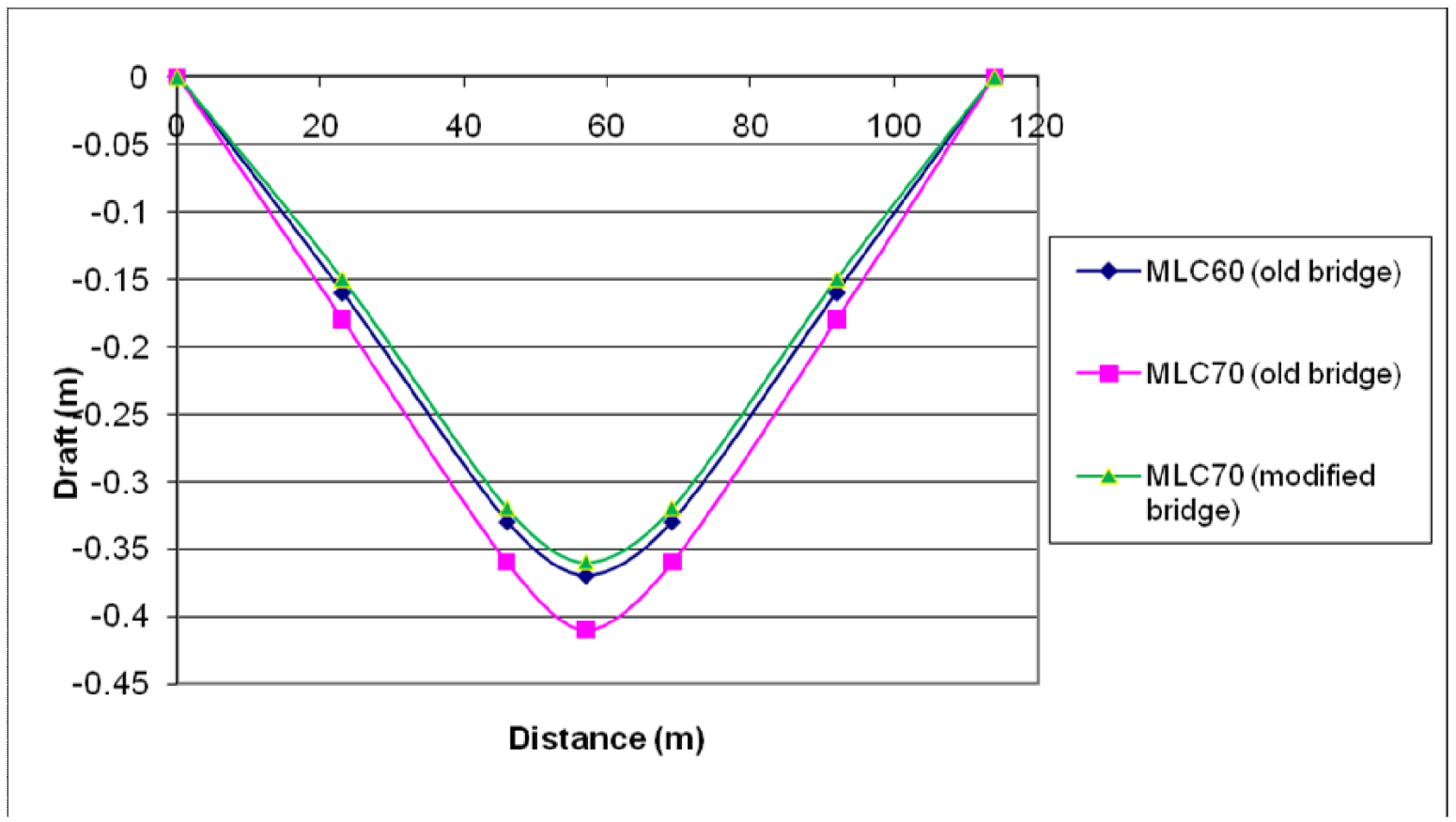


Figure (4.3.4) Draft diagram of old and modified continuous bridge under single tank load MLC 60, MLC70, load case (1)

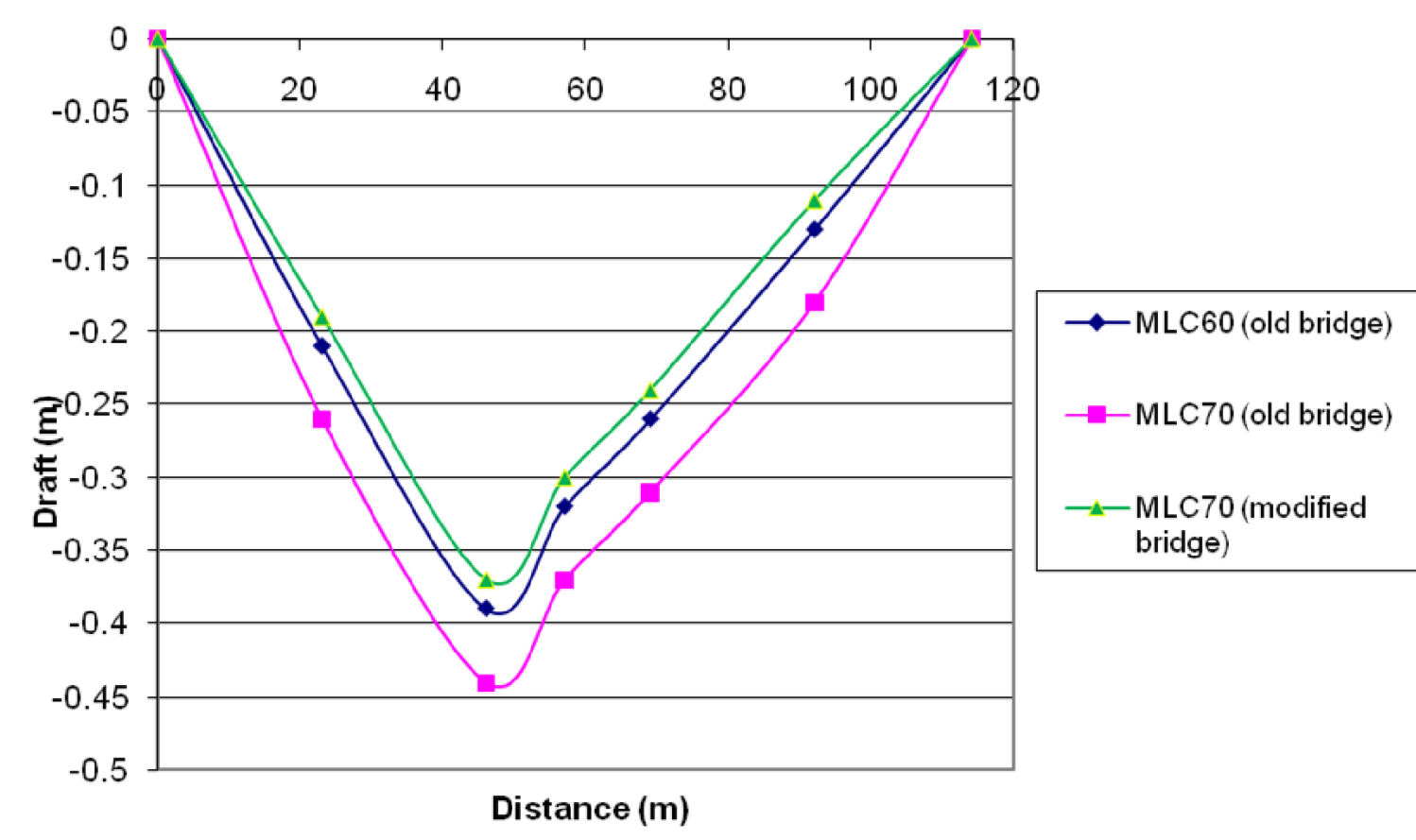

Figure (4.3.5) Draft diagram of old and modified continuous bridge under single tank load MLC 60, MLC70, load case (2)

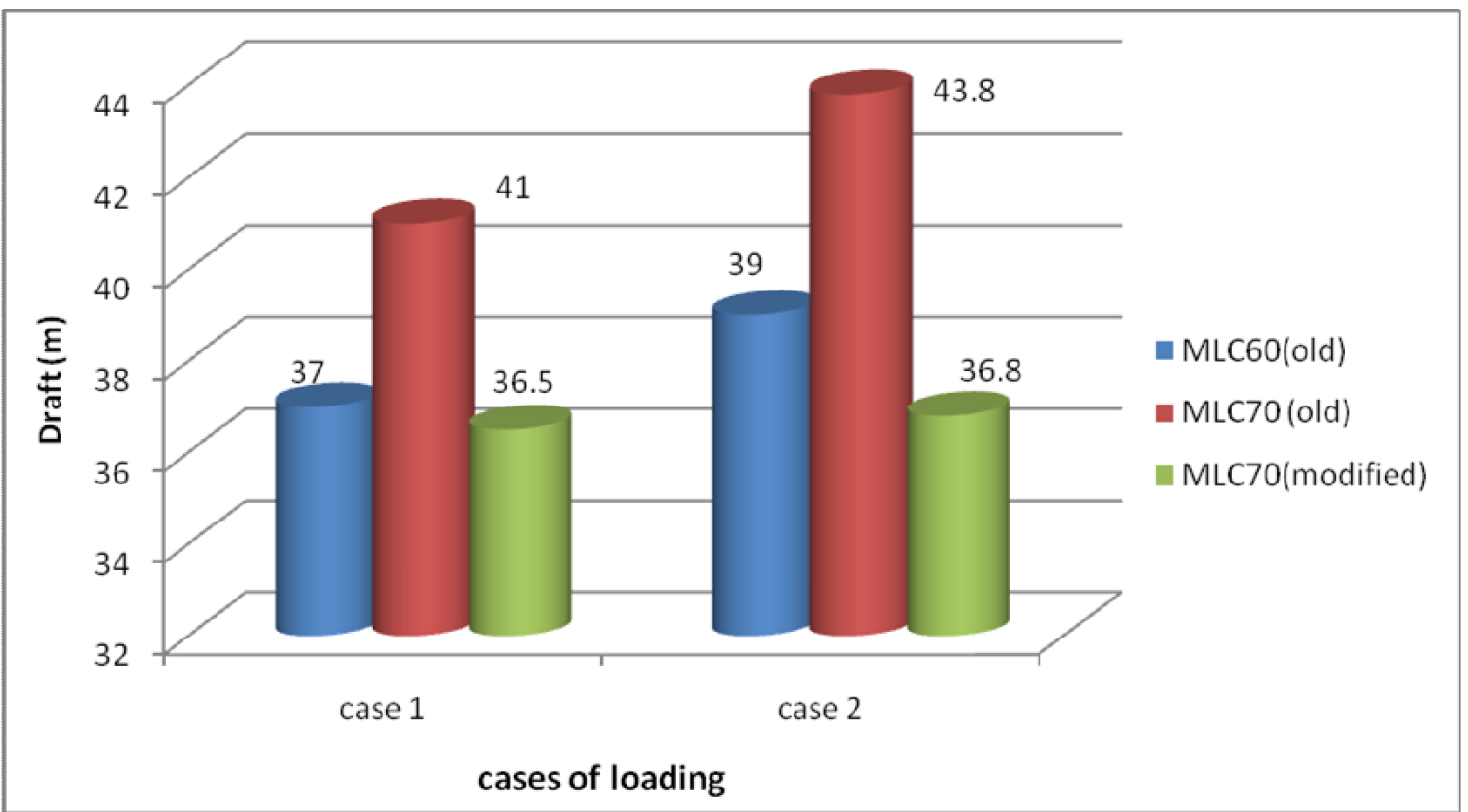

Figure (4.3.6) Comparison between old and modified continuous bridge under single ta nk load (MLC60, MLC70) 


\section{Double tank loading 5.1. Two tanks (MLC60) loading}

Traffic loading of the continuous pontoon bridges must be done under the regulations and limits stated in the military code regarding the spacing between the tanks which sho uld not be less than 50ms at crossing operations. Also, the speed of the tanks during crossing must not exceed $25 \mathrm{~km} / \mathrm{hr}$. Three cases of loading under both (MLC60, MLC70) were modeled in order to analyze the most critical cases of loading on the bridge.

The case study as described before is a bridge of $114 \mathrm{~ms}$ length where two tanks are able to be on the bridge according to the code regulations. Three cases were performed as shown in (5.1), (5.2) and (5.3). In load case (3), one tank is located at C.L of the bridge while the second tank is located at 46ms from C.L. In load case (4), both tanks are located symmetrically at $23 \mathrm{~ms}$ from C.L. In load case (5), one tank is located at $14 \mathrm{~ms}$ from C.L while the second tank is located at $32 \mathrm{~ms}$ at other side from C.L.

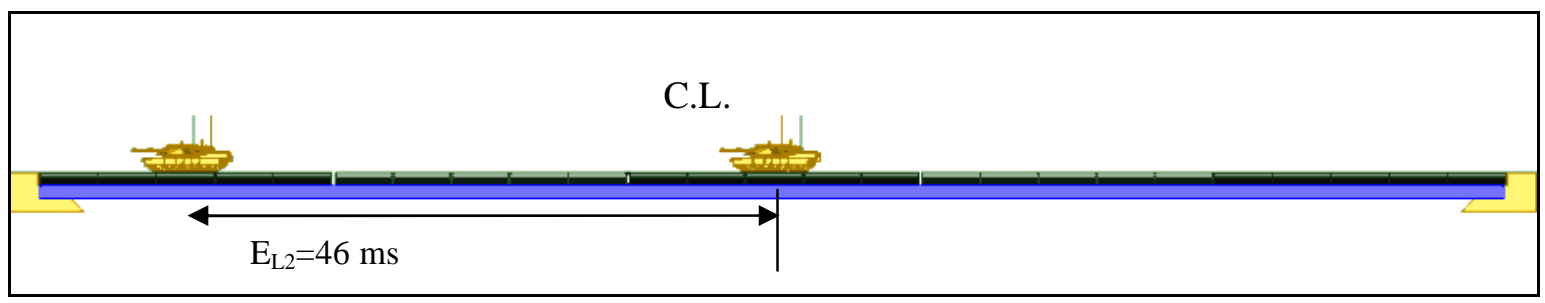

Figure (5.1.1) Load case-3

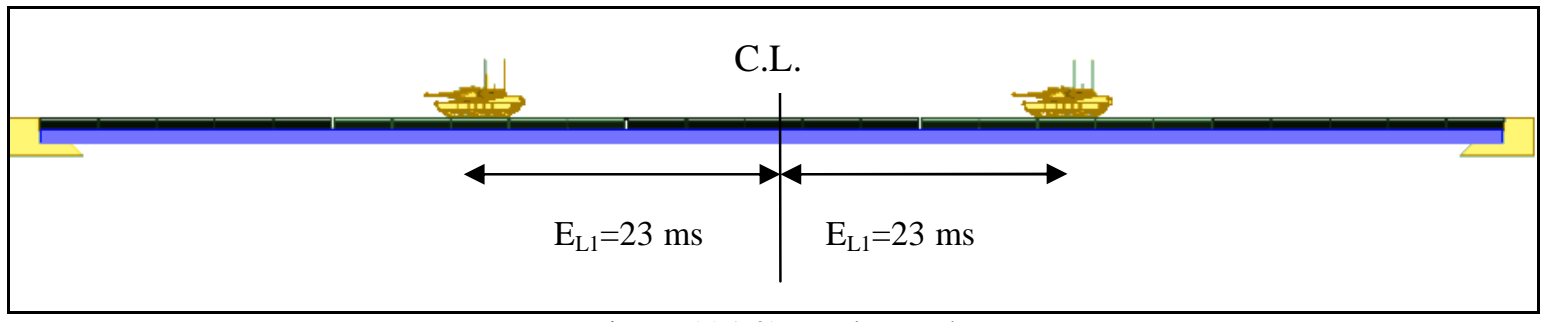

Figure (5.1.2) Load case-4

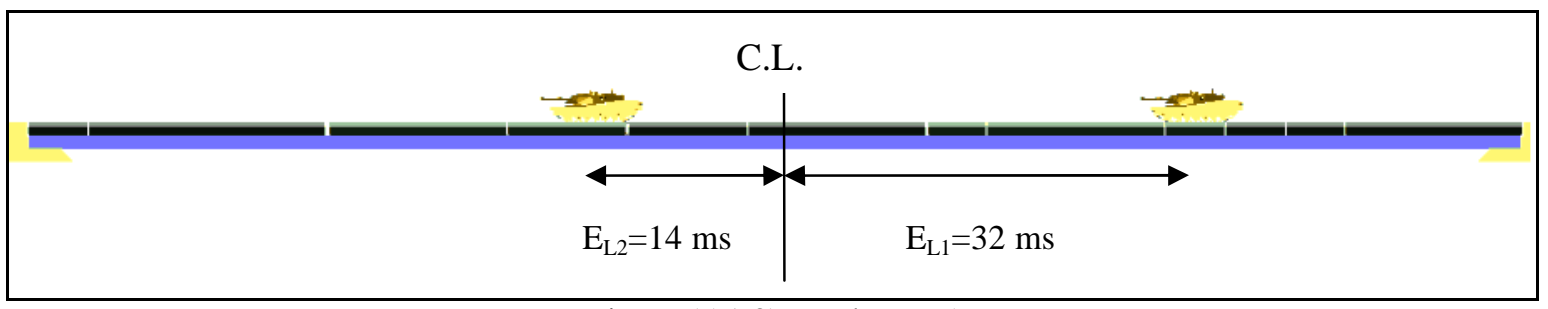

Figure (5.1.3) Load case-5 


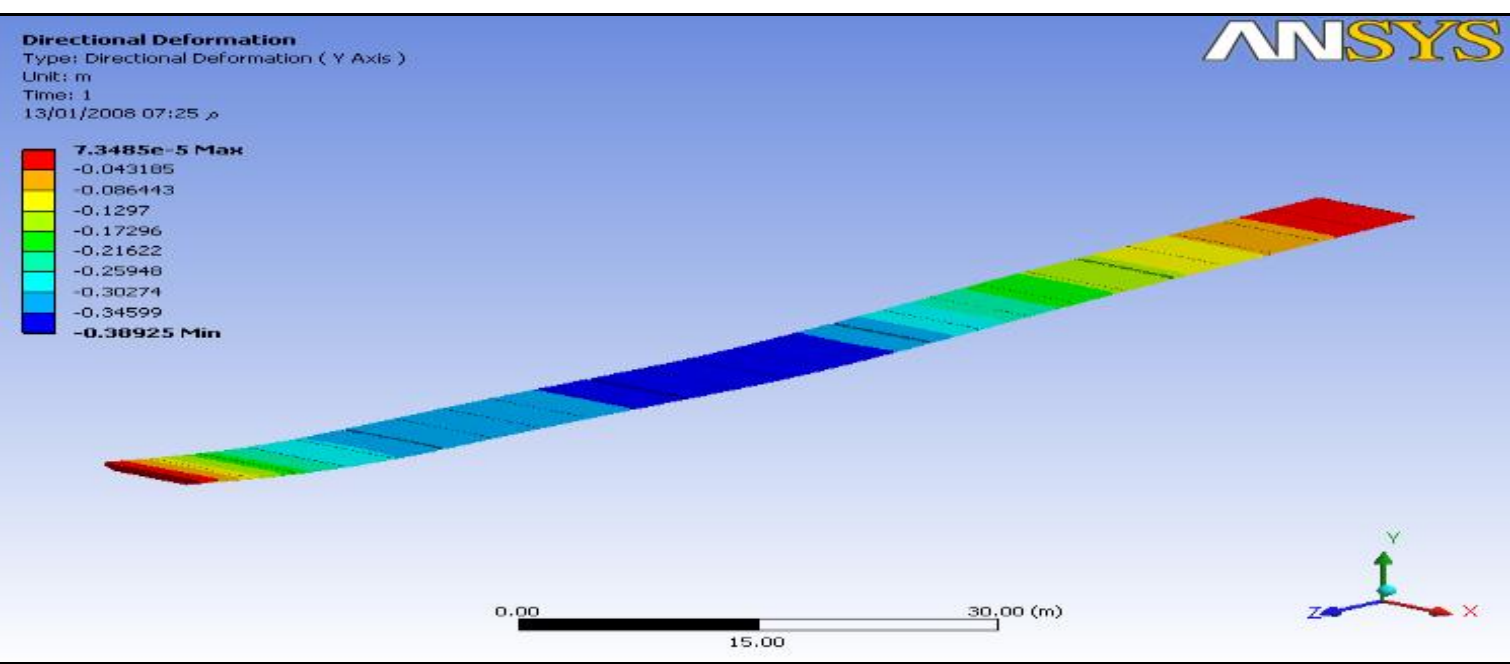

Figure (5.1.4) Draft of the continuous bridge under two tanks MLC 60 (loading case-3)

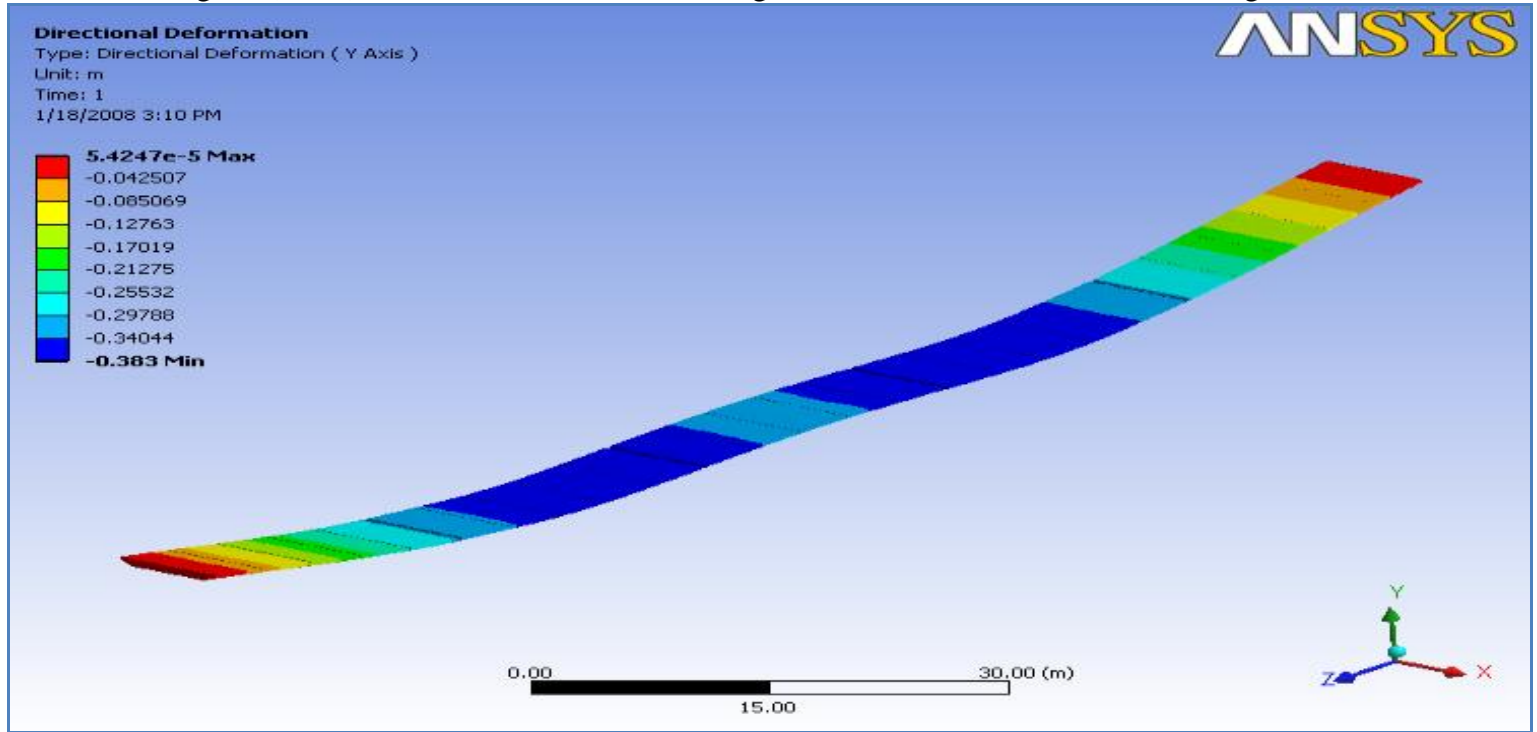

Figure (5.1.5) Draft of the continuous bridge under two tanks MLC60 (loading case-4)

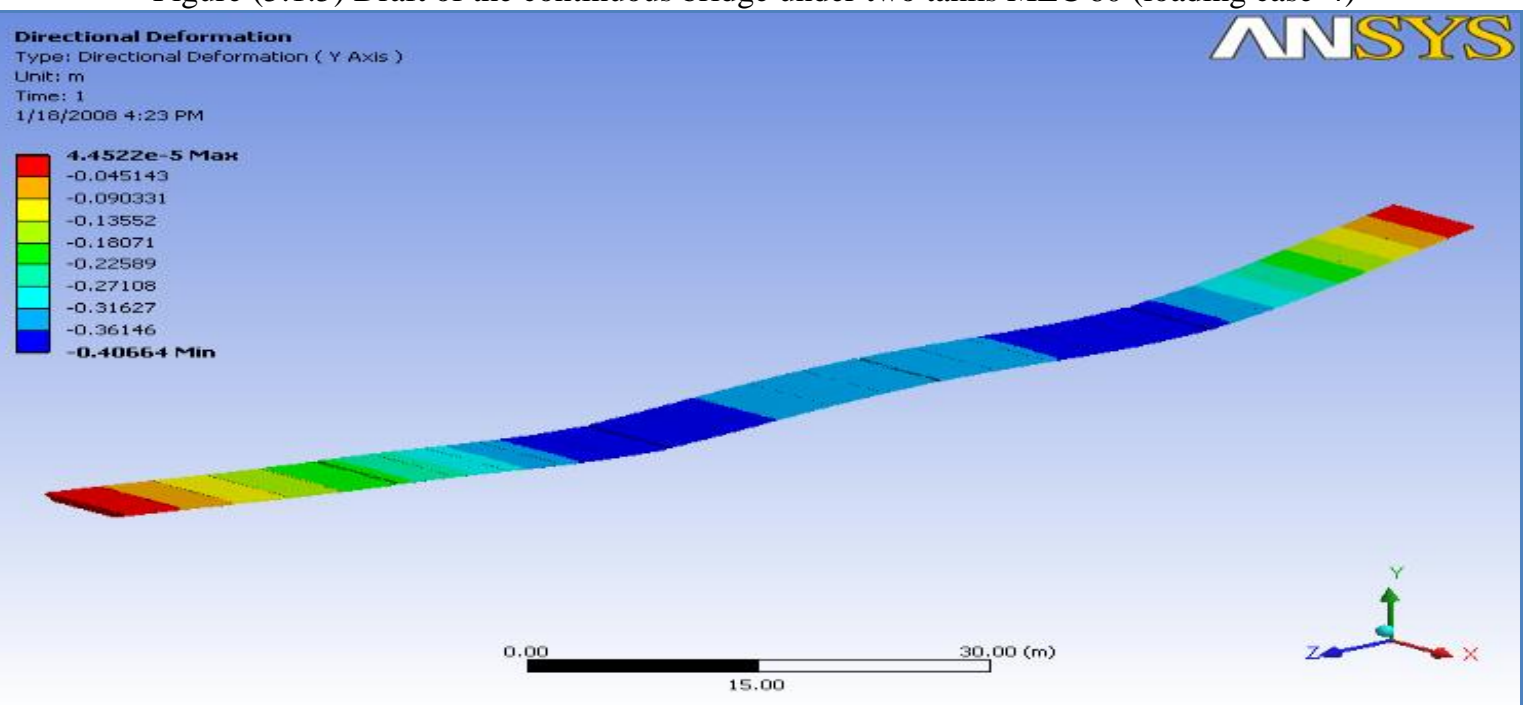

Figure (5.1.6) Draft of the continuous bridge under two tanks MLC 60 (loading case-5) 
The finite element modeling of the old continuous bridge under two tanks MLC 60 shows the behavior of the bridge in different stages of the crossing o peration. The maximum draft under load case (3) is found to be $39 \mathrm{cms}$ which represents $52 \%$ of the bridge height, while load case (4) draft is $38 \mathrm{cms}$ which represents $50.6 \%$ of the bridge height, and load case (5) draft is found to be $40.7 \mathrm{cms}$ which represents $54.3 \%$ of the bridge height, as shown in figures (5.1.4), (5.1.5) and (5.1.6).

\subsection{Two tanks MLC70 loading}

The same loading cases previously discussed are also analyzed under tank load MLC 70.

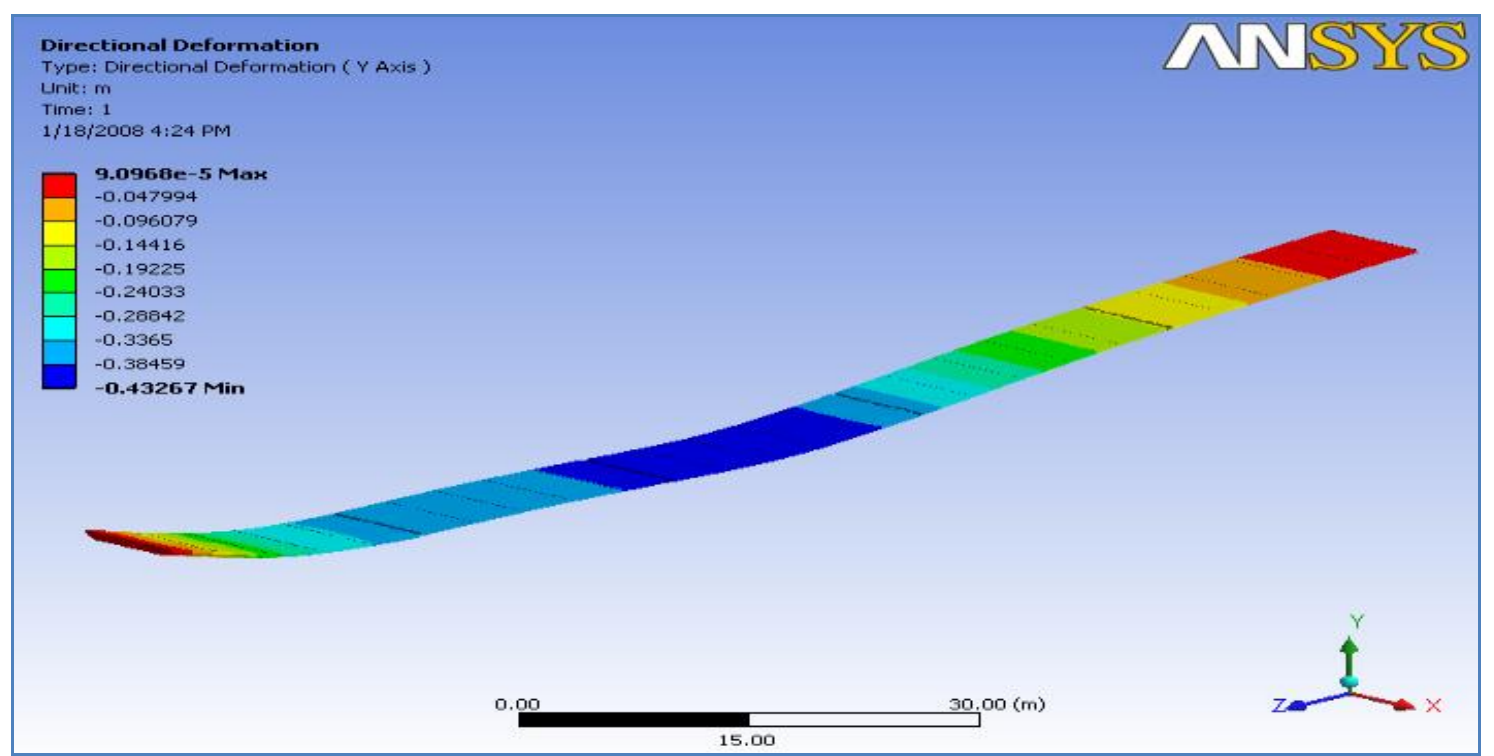

Figure (5.2.1) Draft of the continuous bridge under two tanks MLC70 (loading case-3)

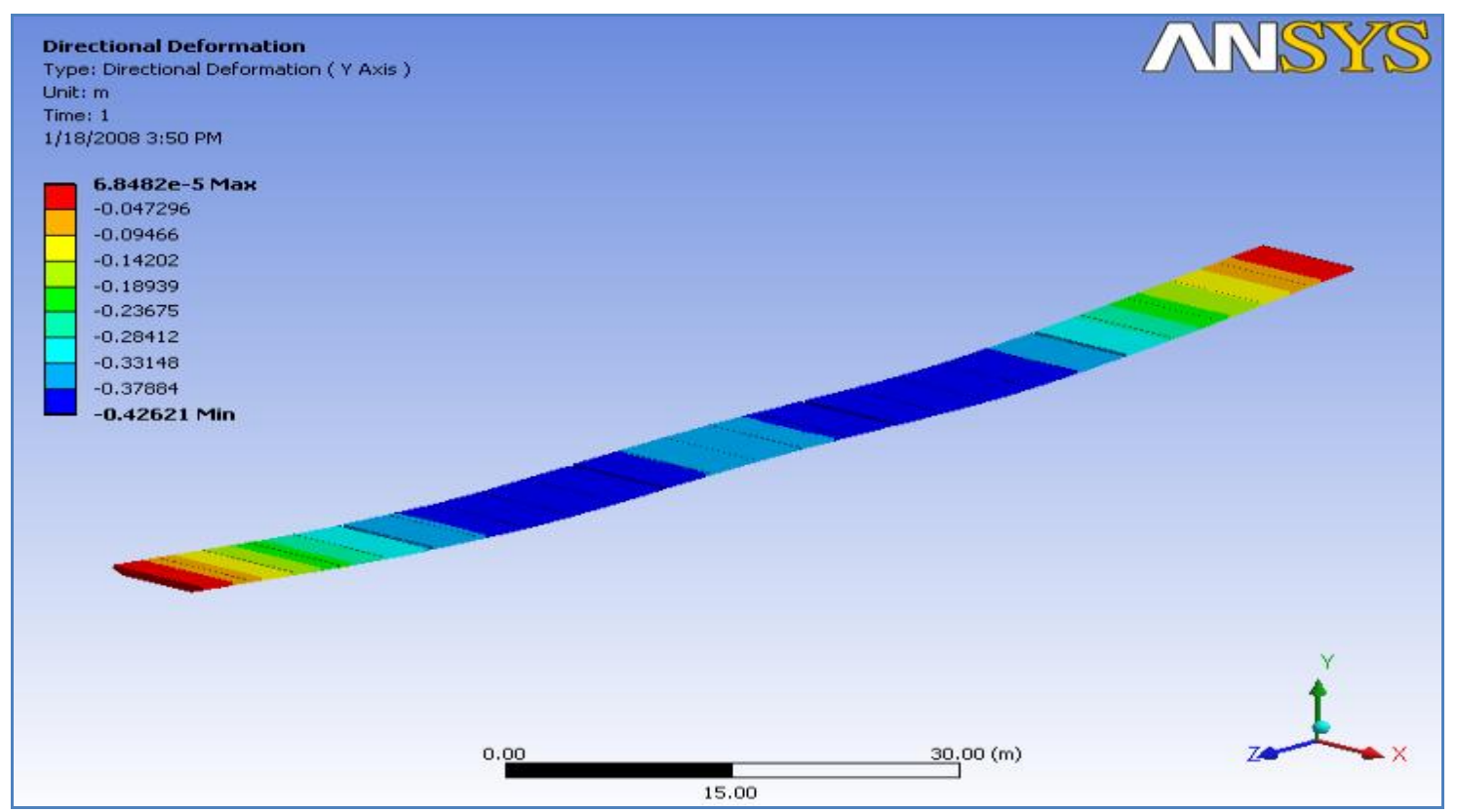

Figure (5.2.2) Draft of the continuous bridge under two tanks MLC 70 (loading case-4) 


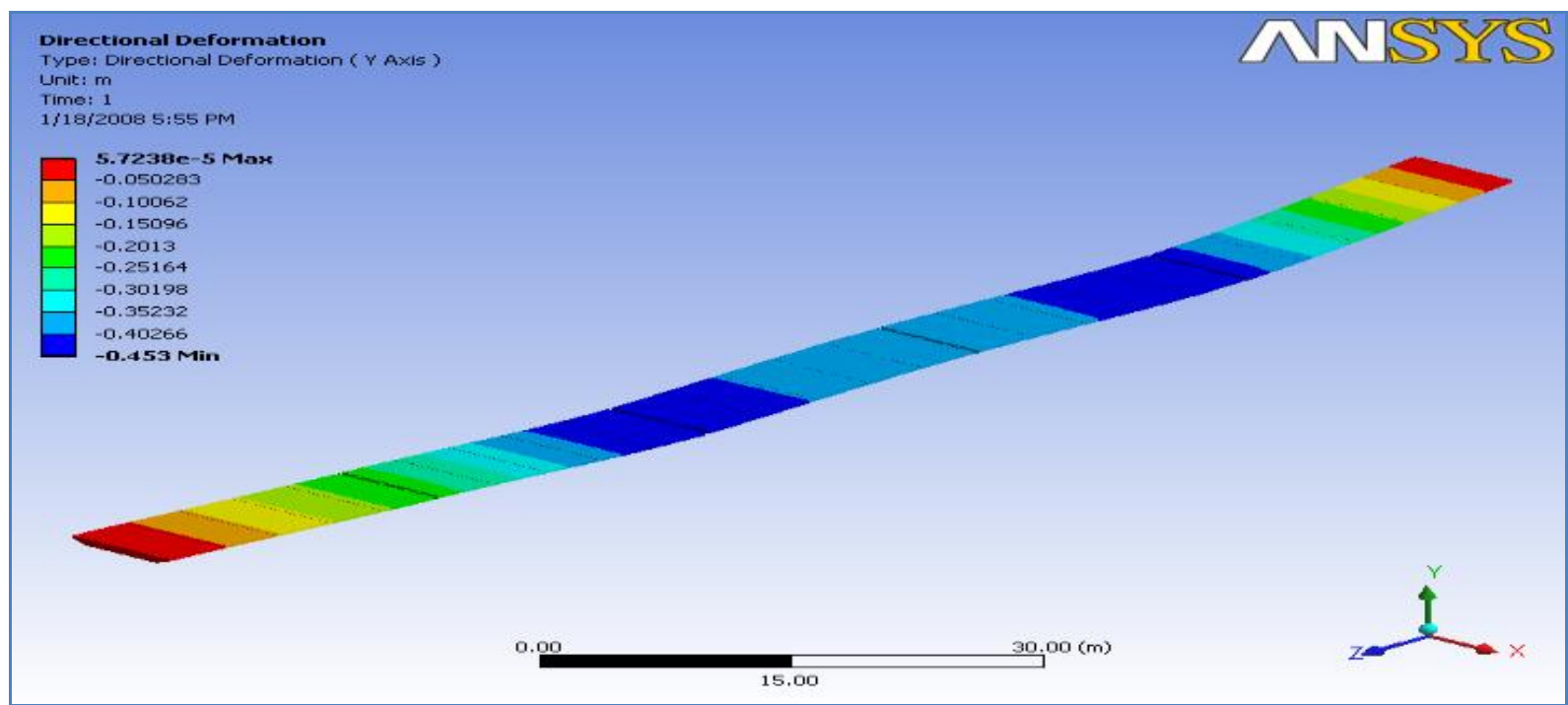

Figure (5.2.3) Draft of the continuous bridge under two tanks MLC 70 (loading case-5)

The analysis of the old continuous bridge under two tanks (MLC70) show that the maximum draft is found to be $43.2 \mathrm{cms}$ in load case (3) and this value represents $57.6 \%$ of the bridge height, while it is found to be $42.6 \mathrm{cms}$ in load case (4) which represents $56.8 \%$ of the bridge height and it is found to be $45.3 \mathrm{cms}$ in load case (5) which represents $60.4 \%$ of the bridge height, as shown in figures (5.2.1), (5.2.2) and (5.2.3).

\subsection{Two tanks MLC70 loading on the modified bridge}

The same loading cases previously discussed are analyzed under MLC 70 acting on the modified continuous bridge.

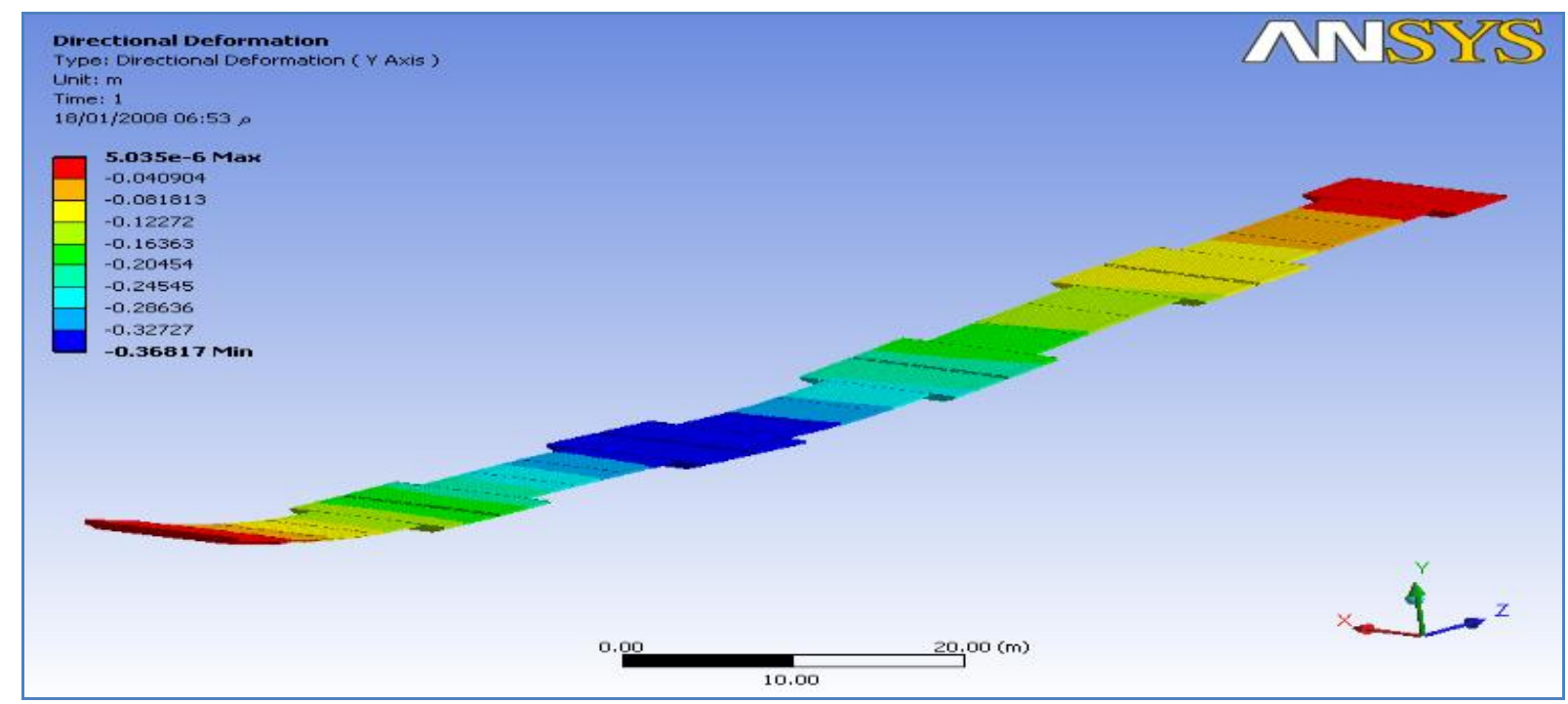

Figure (5.3.1) Draft of the continuous modified bridge under two tanks MLC 70 (loading case-3) 


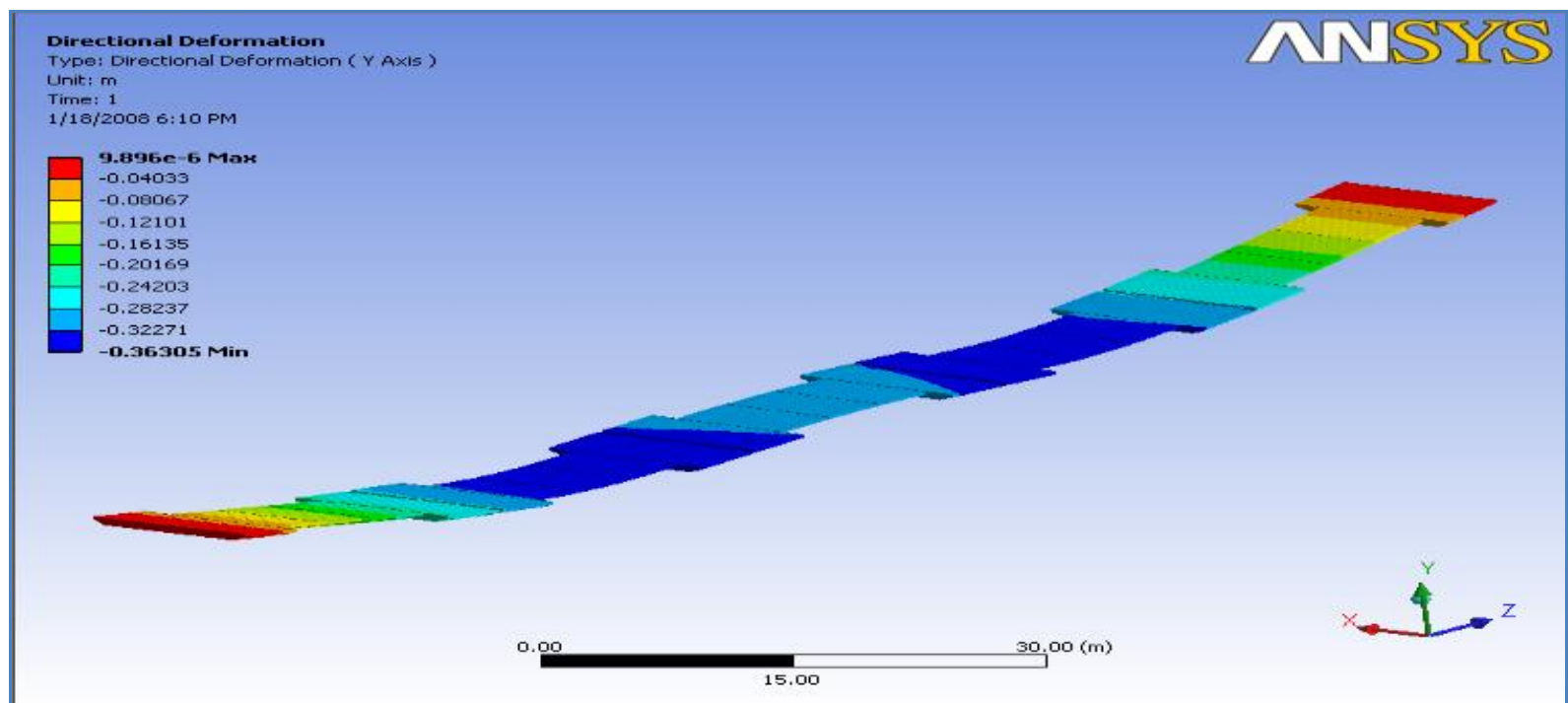

Figure (5.3.2) Draft of the continuous modified bridge under two tanks MLC 70 (loading case-4)

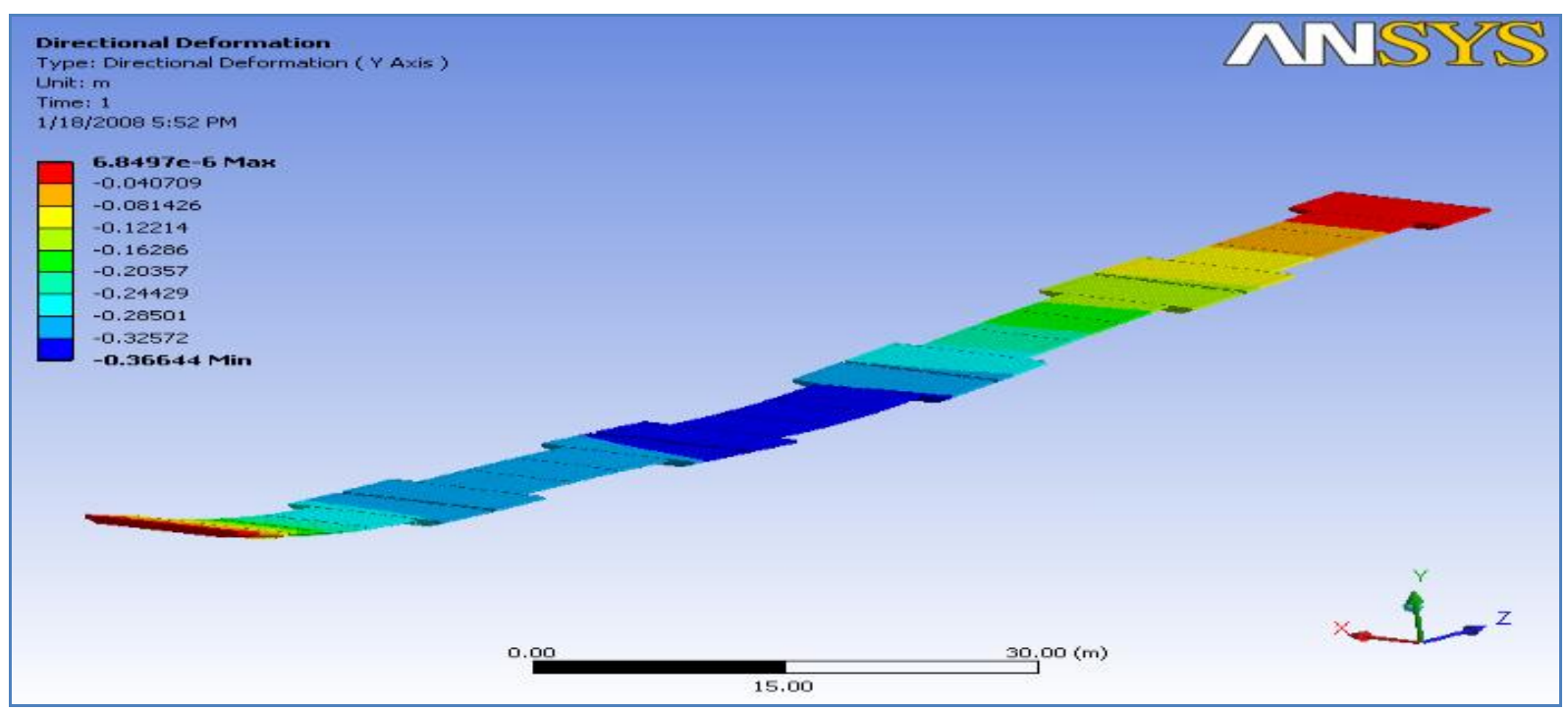

Figure (5.3.3) Draft of the continu ous modified bridge under two tanks MLC 70 (loading case-5)

As shown in figures (5.3.1), (5.3.2) and (5.3.3) the analysis of the modified continuous bridge under two tanks (MLC70), the maximum draft was found to be $36.8 \mathrm{cms}$ in load case (3) and this value represents $49 \%$ of the bridge height, while it was found to be $36.3 \mathrm{cms}$ in load case (4) which represents $48.4 \%$ of the bridge height while it was found to be $36.6 \mathrm{cms}$ in load case (5) which represents $48.8 \%$ of the bridge height. The modification reduced the $\mathrm{dr}$ aft/depth values by $15 \%, 14.7 \%$ and $20 \%$ for third, fourth and fifth cases of loading respectively as shown in figure (5.3.7). 


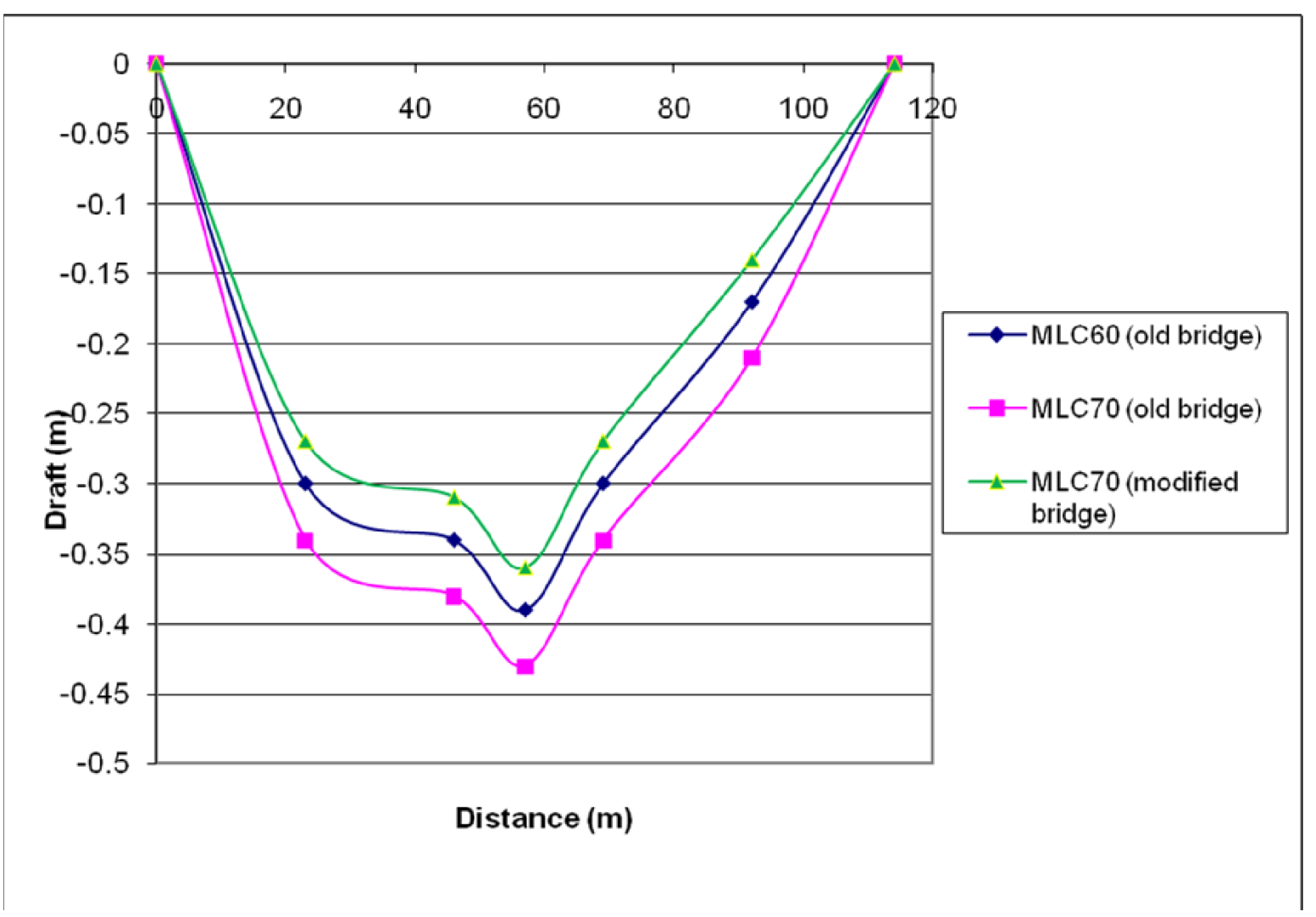

Figure (5.3.4) Draft diagram of old and modified continuous bridge under two tanks MLC 60 and MLC70, load case (3)

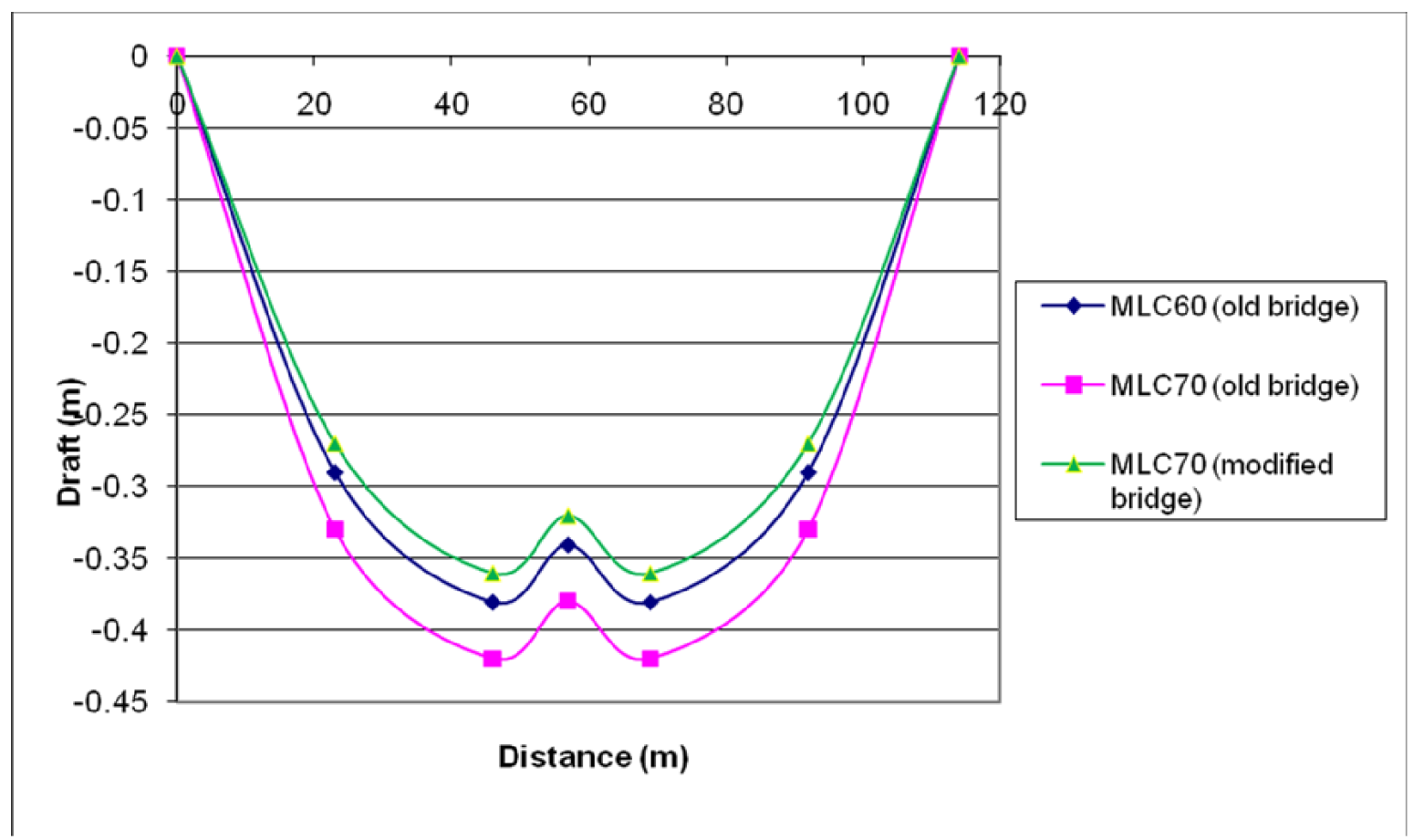

Figure (5.3.5) Draft diagram of old and modified continuous bridge under two tanks MLC 60 and MLC70, load case (4) 


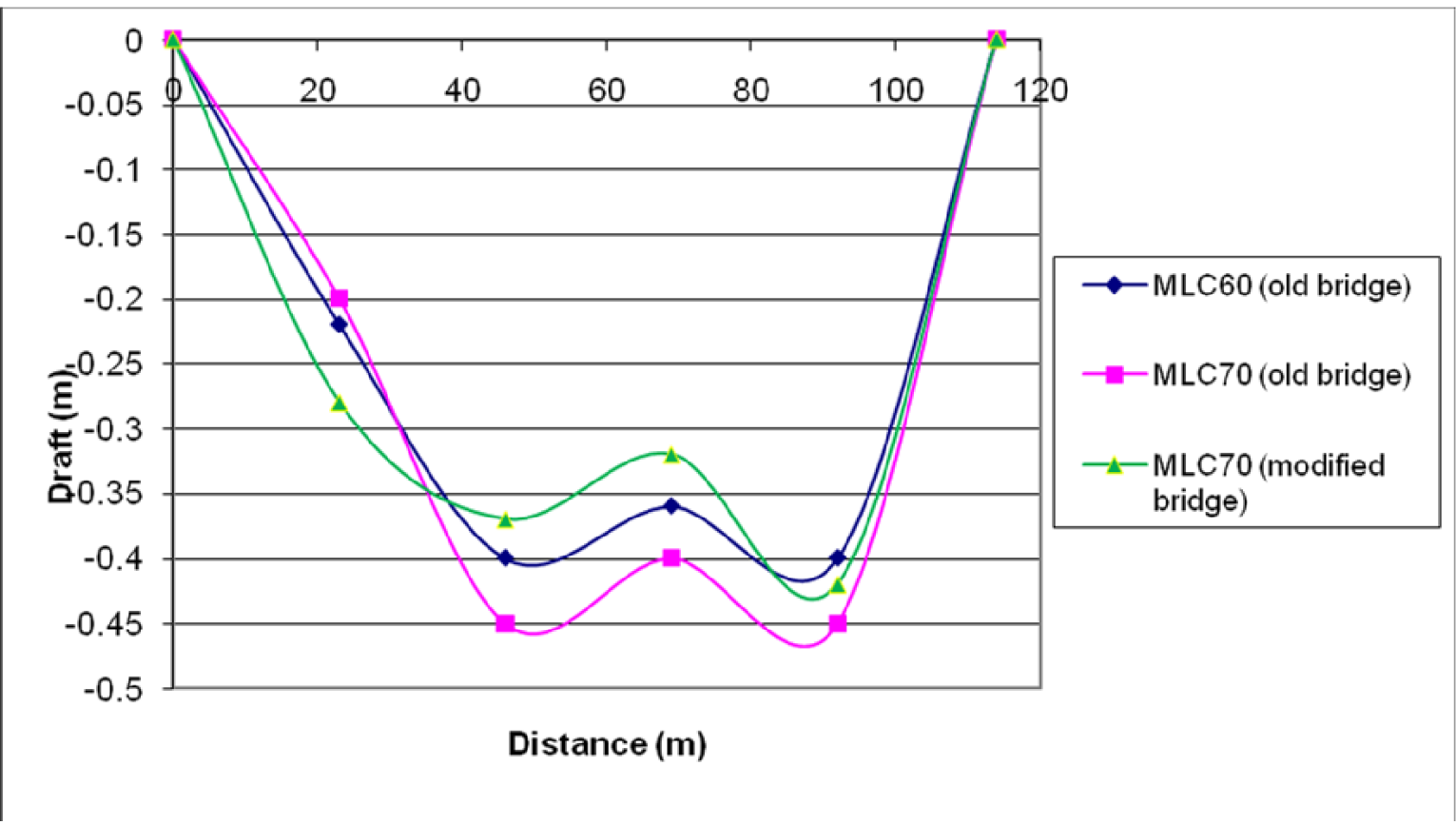

Figure (5.3.6) Draft diagram of old and modified continuous bridge under two tanks MLC 60 and MLC70, load case (5)

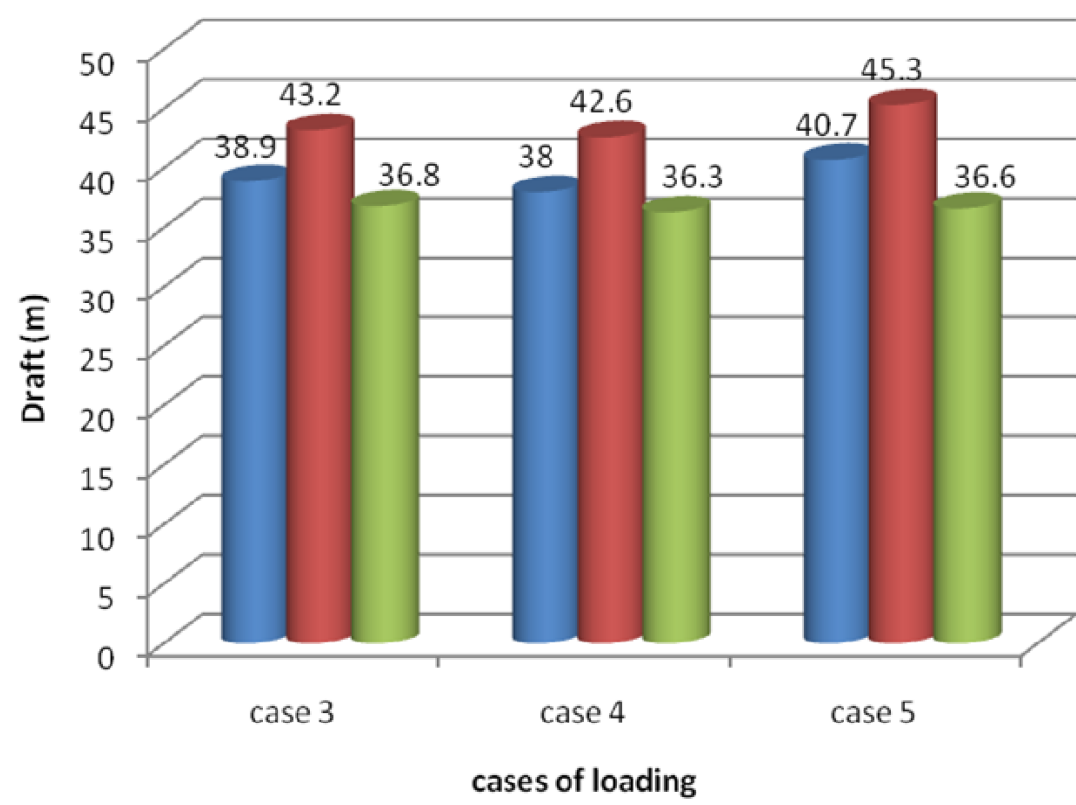

aLC60(old)

aLC70(old)

MLC70(modified)

Figure (5.3.7) Comparison between old and modified continuous bridge under two tanks MLC 60 and MLC70, under the three cases of eccentric loading 


\section{Conclusion}

1- The 3D finite element modeling is the best method for ferries and floating bridges analysi s, as it shows the real behavior of the structure.

2- The 3D FEM for the old (existing) continuous floating bridge showed that the values of draft are 36.5, $36.8,36.8,36.3$, and 36.6 for the five cases of loading presented respectively .

3- The 3D FEM for the modified continuous floating bridge showed that the values of draft are 41.3, $43.8,43.2,42.6$, and 45.3 for the five cases of loading presented respectively .

4- The 3D FEM for the modified continuous floating bridge showed that the modification decre ases the values of draft/depth by $12 \%, 19 \%, 17 \%, 17 \%$, and $23.7 \%$ for the five cases of loading presented.

\section{References}

[1] Eiichi Watanabe "Floating bridges: past and present", Structural engineering international (2003).

[2] M. S. Seif, R. T. Paien Koulaei "Floating bridge modeling and analysis", Scientia Iranica, 12 (2005) 199-206.

[3] Richard W. Dean “Amphibious float bridge systems”, SBLM (2002).

[4] Ehab M. Ebaied "Analysis and design of floating bridges" PhD. Ain Shams University (2007).

[5] Yasser A. Khalifa "Structural System Effect on the Stability on the Metallic Floating Bridges" Msc. MTC (2008)

[6] Masahiko Fujikubo, Tetsuya Yao "Structural modeling for global response analysis of VLFS", Marine structures 14 (2001) 259-310.

[7] Army TM 5-600 "Bridge inspection, maintenance, repair", Department of USA army (1994).

[8] Army FM 90-13 “River crossing operations”, Department of USA army (1992).

[9] "Trilateral Design and Test Code for Military Bridging and Gap -Crossing Equipments", Department of USA army (1996). 